\title{
A Research on Cloud Computing Adoption Practices in the Context of Online Business SMEs in Sri Lanka
}

\author{
Ahamed Lebbe Mohamed Ayoobkhan
}

\begin{abstract}
The purpose of the study was to explore the Cloud computing Practicing level, Cloud computing Satisfaction level and the Preferred Cloud service provider among the Online Business SMEs (OBSMEs) in Sri Lanka that have adopted Cloud services. Prior studies have shown that SMEs significantly benefit due to the adoption of Cloud computing services. The study was conducted among 260 randomly selected OBSMEs using self-administered questionnaires from managerial and ICT professionals who were capable of making ICT decision at OBSMEs under this study. However only 247 questionnaires were returned with complete data required for the purpose of analysis. A descriptive analysis was used to analyse the data. The findings have revealed that $31 \%$ of the OBSMEs are frequently Practicing Cloud computing for their ICT needs, while 69\% of them relies on Cloud computing for their different ICT needs usually. Findings reveals that 35\% of the OBSMEs are moderately Satisfied in this study, while $61 \%$ of OBSMEs have been reported that they are very Satisfied with Cloud computing services, at the same time 4\% of the OBSMEs are reported that they have extremely Satisfied with Cloud computing services. In the context of OBSMEs it has been reported that $78 \%$ of the Cloud service providers are rendering reliability of services and OBSMEs are very satisfied, while $12 \%$ of the OBSMEs are moderately satisfied with the reliability of services and other $10 \%$ of the OBSMEs are extremely satisfied with the reliability of services provided by Cloud Service Providers in Sri Lanka. This study extends the existing body of knowledge by providing empirical support for explaining cloud computing adoption by OBSME in Sri Lanka. The study add value for various parties engaging in promoting the adoption of cloud computing among various business industries in Sri Lanka. Therefore, the researchers are able to recommend that cloud computing technology is playing a significant role for the improvement of business industries in Sri Lanka and the software vendors, policy makers and technological service providers should consider the findings of this study if they have intention to adopt this technology in future. Moreover, the findings of this research would assist and enhance service providers to consider their investment in information technology when adopting and implementing Cloud computing in Sri Lanka.
\end{abstract}

Keyword: Cloud Computing, Online Business SMEs, Cloud adoption, SMEs Cloud

\section{INTRODUCTION}

Scholars argues that Small and Medium Enterprises (SMEs) have been recognized as a major contributors of economic development of a country because it contributes to generate employment, accelerate economic growth and reduce poverty, income inequality, inflation and balance of payment. Effective SMEs are a significant element of

\footnotetext{
Revised Manuscript Received on November 19, 2019

Ahamed Lebbe Mohamed Ayoobkhan, Faculty of Management and Commerce, South Eastern University of Sri Lanka, Oluvil, Sri Lanka.(Email: ayoob@seu.ac.lk)
}

innovation change and social benefits for all economies across all countries [2] \& [19]. Instead, continuous development and use of technological advances, new innovative communications technology tools and applications are providing numerous opportunities for SMEs in order to use it [3] \& [24]. Researchers argue that there are many positive effects on SMEs by using innovative communication technology such as customer awareness and efficiency gains are economic advantages. ICT innovation adoption studies have reviewed that this sector should be continually growing and expanding. In particular, ICT relates to the implementation and adoption of SME systems. The adoption and extensive challenges of ICT in SMEs have changed dramatically [1] \& [9]. Cloud Computing is becoming a prominent technology in the world. It offers variety of opportunities that help the organizations to improve their business and use technology more efficiently. Many organizations have started adopting cloud computing in their business. It is difficult for the organizations to survive in the traditional ways and they are unable to compete with their competitors. Especially in this competitive environment, respond quickly to business demands is necessary. The organizations are necessary to implement strategic ideas to gain competitive advantages. Cloud computing is an enhanced technology and become a vital technology to run business. It acts as an excellent technological tool that helps the organizations to stay competitive as it can be considered as an innovative way to increase business value. It enables the users and consumers to integrate and combine many different services together that increases the creativity and productivity [27]. Businesses are not resistant to these effects and must find a way to effectively adopt such new technologies. The issues related to maintaining, selecting, updating and managing information and communication technology are particularly challenging for SMEs [12], [4], [20], [11] \& [22]. Cloud computing has been playing a major role in solving the inefficiencies problem in organizations and increase the growth of business thus help the organizations to stay competitive. Many companies are seeking an alternative solution that reduces the total cost of their ICT systems, while some choose to outsource them to the third party [15] \& [24]. According to [19], in brief, overall, Cloud computing enables the organizations to manage their business efficiently. 
Cloud computing enables the dynamic computing capacity, storage capacity, network exchanging capacity and information service capacity. Cloud computing serves the users as "pay-as-service" based on their demand. Cloud Computing provides new service modes such as "IaaS" (Infrastructure as a Service), "PaaS" (Platform as a Service), and "SaaS" (Software as a Service) [24]. This technology have become a serious target for information systems development; it provides companies with different advantages such as resource pooling, quick flexibility, wide network access...etc. [15]. The use of new technologies such as cloud computing allows many companies to gain competitive efficiency and allow them to increase efficiency and productivity [17]. Thus more and more organizations start migrating their services and applications to cloud. Cloud computing has been used and applied in organizations and it helps to gain revenue every year [1] \& [3]. Various studies have been discussed about the Technological, Organizational and Environmental factors (TOE) that impact the Cloud computing adoption. Hence, analysis of this technology is still essential in various business segments for better understanding of Cloud computing [11].

\section{INTERNET USAGE AND ONLINE BUSINESS TRENDS IN SRI LANKA}

After the end of the war in 2009, Sri Lanka has recorded strong growth in economic and Internet penetration rates. The rate of internet penetration of Sri Lanka has been recorded around 35\% in the year 2017 (http://www.trc.gov.lk). A report released by the Department of Census and Statistics 2017 indicates that Sri Lanka has a higher literacy rate than other South Asian countries. At the same time, the average income of Sri Lankans is higher than that of India, Pakistan, Bangladesh and Afghanistan; the move will bring online business companies to a stronger position in the region. Central bank report of Sri Lanka indicates that there is a notable upward trend, as in September 2017; there are $1,515,299$ credit cards are active. Of these, 41,289 are accepted only locally, while 1,474,010 (over 94\%) are accepted internationally. According to the above indication, Sri Lanka is witnessing a massive surge in computer usage and internet penetration; though very few SMEs are adopted Cloud computing in their business activities in Sri Lanka.

Total Internet connections increased by 78.4 percent in 2017 (www.trcl.lk), largely supported by the growth of mobile internet usage, according to a central bank report. This growth is driven by the active use of information and communication technology (ICT) services in economic activities such as e-banking, mobile banking, e-bus tickets and mobile points of sale (POS). The Central Bank of Sri Lanka 2017, www.lankabusinessonline.com and www.ips.lk indicate that the contribution of SMEs to GDP is $53.4 \%$, which is higher than that of South Asian countries, but the contribution of online business SMEs (OBSMEs) is approximately $4.3 \%$ of GDP. This is low compared to countries like Pakistan, Bangladesh, Nepal and India.

\section{LITERATURE REVIEW OF THE STUDY}

As indicated by [14], the development of this new technology is changing the way business information systems are created, measured, maintained and paid whether the business organizations are big or small. This technology promises to improve productivity and reliability of the SMEs by allowing business organization to focus their limited resources on their core business [14], [11] \& [15]. Most researchers and stakeholders who are concerned about the adoption and diffusion of new ICT innovations usually focus on some key questions. What is the status and what are the factors that determine the rate, pattern and size of the diffusion of an invention across the population of potential adopters. According to [20], [3], [24], [11] \& [22], the factors that determine a company's general prediction for adopting and integrating innovation over time and the factors that determine a company's motivation for adopting and integrating innovation are different. According to [24], a number of significant gaps still exists, after reviewing the extensive literature on ICT adoption and dissemination, even with considerable effort and attention devoted to ICT adoption research. As mentioned by [18], Most of the inconclusive findings of this research are due to factors such as differences in the ICT findings studied, different methods of data collection, differences in the functioning of structures, and differences in the context of innovation. As a result, it is not yet clear what differentiates SMEs from adopting ICT innovations. More specifically, this technology is concerned, and there is no systematic research on how SMEs evolve with the adoption of cloud computing, and what the technological, organisational and environmental factors and changes associated with this decision-making process and factors can vary based on the context and surrounding environment.

Furthermore, while there are few prior studies on cloud adoption in SMEs, there are a small number of studies examining this technology in the context of developing countries [19], [6] \& [16]. As noted in [21], influencing factors vary depending on the environment and the surrounding environment, therefore these issues should be studied in the context of their own environments. Most past research merely considered Cloud computing as a technology adoption issue, but this should be considered a combination of technology adoption and service adoption, giving more weight to business adoption from business point of views.

As mentioned by [24], most of the literature on Cloud Computing has widely focused on Cloud Computing architecture [17], potential applications [10], Cloud Computing costs and benefits [5], and focused only on a particular type or service model of Cloud Computing. But dearth of studies that mainly focus on cloud computing adoption which should be studies first. Research study by [25] has focused solely on adoption of SaaS by organizations. Many previous research studies in Cloud Computing adoption have focused only on the technological aspects of adoption in this emerging innovation [11]. For example, they have focused exclusively on areas such as technology complexity, technology compatibility, security requirements, and future expectancy [11]. Moreover, while there are some prior studies on Cloud adoption in SMEs [19] \& [16], there is a lack of studies examining the adoption of Cloud computing 
especially considering micro, small and medium-sized organisations separately. [1], [8] \& [18] have studied that "the performance of hospital industries will be increased by adopting this technology in order to reduce expediters that occur for ICT maintenance cost in the context of Sri Lanka". Studies so far conducted in Sri Lanka, are very less focused on Cloud computing adoption in SMEs, particularly in online business organizations, despite this being one of the major concerns in other countries but no studies so far focused in the field of adoption of Cloud computing in online business SMEs in Sri Lankan, particularly to examine the existing conditions of the Cloud computing adopted organizations.

The focus of this research is on SMEs within Sri Lankan context, understanding why and how online business SMEs are motivated to adopt Cloud computing and will enable the creation of a more encouraging environment for greater adoption and will help in developing strategies to promote the adoption process. When a new innovation is introduced, a greater understanding of the factors influencing its adoption will result in an increase in adoption [2]. Therefore, from the background of the studies, it is clear that poor attention has been paid by the researchers in Sri Lankan context, the factors that impact SMEs' decisions towards the adoption of Cloud computing in online business organizations. Moreover, the rare research done in the Sri Lankan context on this technology is in a different domain, clearly showing that security risks, lack of awareness and cost are the main reasons for the unusual lower usage of this technology in SMEs. Other studies have indicated that other than these barriers; Top management support, regulatory responsiveness, and complexity were discouraging factors from the SMEs' point of view. It is an accepted fact that adopting and expanding the use of this technology can significantly reduce the operating costs of business enterprises, increase accuracy, efficiency and improve their profitability. Therefore, the main focus of this research is to explore the cloud computing practices of OBSMEs in Sri Lanka, the level of cloud computing satisfaction of OBSMEs and the preferred cloud computing service providers by OBSMEs adopting this technology. Further, the outcome of this study may assist in strategic planning from the perspectives of other SMEs sectors that are planning or are in the process of implementing a review of their Cloud computing initiatives, and Cloud service providers using Cloud technology to gain a competitive edge.

\section{RESEARCH METHODOLOGY}

This research study have engrossed on Cloud computing adopted OBSMEs in Sri Lanka and its aspect of firm's innovativeness. In order to achieve the set research objectives, this study explores the status of Cloud computing Practicing levels, Cloud computing Satisfaction level and the Preferred Cloud service provider among the Online Business SMEs (OBSMEs) in Sri Lanka. This study hence broadly adopted two prominent theories namely Diffusion of Innovation (DOI) theory of Rogers (1962) and the Technology, Organization, and Environment (TOE) framework of Tornatzky and Fleisher (1990). The DOI theory holds that individual, structural and external characteristics of organizations are important antecedents to organizational innovativeness. The TOE framework on the other hand affirms that three such contexts namely technological, organizational and environmental contexts of an enterprise impact on technological innovation of a firm. There are previous studies that have employed DOI and TOE framework to explore the IT adoption. The population for this study consisted of decision makers of OBSMEs and IT Professionals who are authorized and responsible for both technology acquisition and policy decisions for their organisations. The population of the present study is 489 OBSMES [28]. Hence, the table 1 below explains the responsive rate of the study.

Table 1: The responsive rate of the study

\begin{tabular}{ccc}
\hline Description & Value & Percentage \\
\hline $\begin{array}{c}\text { Total number of questionnaire } \\
\text { distributed }\end{array}$ & 260 & $100 \%$ \\
Total number of responses \\
$\begin{array}{c}\text { received } \\
\text { Adopters of Cloud computing } \\
\text { Non-adopters Cloud } \\
\quad \begin{array}{c}\text { computing } \\
\text { Incomplete responses }\end{array}\end{array}$ & 247 & $95 \%$ \\
\hline
\end{tabular}

\section{DATA ANALYSIS AND FINDING OF THE RESEARCH}

The demographic data of the respondents have been illustrated in the above table 2 , indicates that by gender, the proportions of the male and female are not similar. Majority of the respondent participated in the survey are male $95 \%$ (192), while 5\% (11) are female. Majority of the respondent participated in the survey are aged from 36-50, while others are aged from 26-35. Most of the participants responded in this survey are from Managerial level category who are Senior IT/IS Managers around 105 (52\%), while IT/IS Managers are $41(20 \%)$ and IT/IS Executives are around 57 (28\%). As far as the firm size is concerned, 132 firms are having employee from 1-10 which are smaller than other organizations and it is around $65 \%$ in comparison in this study, while only 13 organizations are having employees more than 13 , it is around $6 \%$ among the respondents.

According to the summarized survey table 4.2, 22 organizations are having IT employees ranging from 1-3, it is around $11 \%$, while 47 organizations are functioning their IT unit by using 4-6 employees, while 81 organizations are using 7-10 employee for their works, it is around $40 \%$ in the survey data. Only $53(26 \%)$ organizations are still functioning with more than 15 IT/IS employees in their unit. 
Table 2: Frequency of Demographic factors of the respondents

\begin{tabular}{|c|c|c|}
\hline Variable & Frequency & Percentage \\
\hline \multicolumn{3}{|l|}{ Gender } \\
\hline Male & 192 & $95 \%$ \\
\hline Female & 11 & $5 \%$ \\
\hline \multicolumn{3}{|l|}{ Age } \\
\hline $26-35$ & 78 & $38 \%$ \\
\hline $36-50$ & 125 & $62 \%$ \\
\hline \multicolumn{3}{|l|}{ Qualifications } \\
\hline Bachelor degree & 125 & $62 \%$ \\
\hline Master degree & 78 & $34 \%$ \\
\hline \multicolumn{3}{|l|}{ Job Category } \\
\hline Managerial level & 146 & $80 \%$ \\
\hline Administrative level & 48 & $24 \%$ \\
\hline Operational level & 9 & $4 \%$ \\
\hline \multicolumn{3}{|l|}{ Positions } \\
\hline Senior IT/IS Manager & 105 & $52 \%$ \\
\hline IT/IS Manager & 41 & $20 \%$ \\
\hline IT/IS Executive & 57 & $28 \%$ \\
\hline \multicolumn{3}{|l|}{ Firm Size } \\
\hline $1-10$ & 132 & $65 \%$ \\
\hline $11-20$ & 4 & $2 \%$ \\
\hline $21-30$ & 37 & $18.2 \%$ \\
\hline $31-40$ & 17 & $8.4 \%$ \\
\hline More than 100 & 13 & $6.4 \%$ \\
\hline \multicolumn{3}{|l|}{ Employee working in IT } \\
\hline Unit & 22 & $11 \%$ \\
\hline $1-3$ & 47 & $23 \%$ \\
\hline $4-6$ & 81 & $40 \%$ \\
\hline 7-10 & 53 & $26 \%$ \\
\hline More than 15 & & \\
\hline
\end{tabular}

\section{CLOUD COMPUTING NON-ADOPTERS}

According to the survey, it has been reported that 44 non-adopter are still in online business who are not yet adopted Cloud computing but using in-house services in Sri Lanka. According to table 3, around 44 (17\%) OBSMEs are still depending on their in-house technology or local services.

Table 3. Cloud adopters and non-adopters

\begin{tabular}{ccc}
\hline & Frequency & Percent \\
\hline No & 44 & 16.9 \\
Yes & 203 & 78 \\
Total & 212 & 94.9 \\
\hline
\end{tabular}

\section{CLOUD COMPUTING ADOPTERS}

The present study of the table 3 have revealed that 203 (78\%) OBSMEs have presently adopted and practicing Cloud computing technology in Sri Lanka. Further, it has been revealed that around $31 \%$ of the OBSMEs are frequently practicing Cloud computing for their ICT needs, while 69\% of the companies relies on Cloud computing for their ICT needs usually. Around 26\% (52) of the OBSMEs have been identified as "Sometime users". They use integration of Cloud Computing services and IT system locally, while around $55 \%$ (111) of the OBSMEs have been identified as "Frequent" users and 20\% (40) of OBSMEs have been identified as practicing "Usually" this technology.

\section{CLOUD COMPUTING SAAS, PAAS AND IAAS ADOPTION BY OBSMES}

The survey report indicates that around 27\% (55) of the OBSMEs are using Software as a Service (SaaS) "Occasionally" for their software needs, while 16\% (32) of the employees are using SaaS for "Sometimes" around 27\% (54) respondents reported that they access SaaS service "Frequently", while 31\% (62) used to access SaaS "Usually". $22 \%$ of the OBSMEs have been reported that they use PaaS "Occasionally", whereas the same is used by $20 \%$ of the respondents "Sometimes". Nearly $41 \%$ of the respondents have been using PaaS "Frequently", while $18 \%$ of the respondents have been using PaaS "Usually" for their routine works. IaaS is one of the three main categories of Cloud computing services, alongside SaaS and PaaS. The survey report revealed that $67(33 \%)$ of the respondents have been using this services "Occasionally", while 54\% (109) respondents have been using this services "Sometimes" and "Frequently" users have been as 13\% (27).

\section{CLOUD COMPUTING SERVICE PROVIDERS IN SRI LANKA}

Cloud providers are sometimes referred to as Cloud service providers or CSPs. According to the table 4 Google is in the top among service providers in Sri Lanka. Aaround 153 $(75 \%)$ of the online business organizations are using Google, while $50(25 \%)$ of the organizations are not using Google. Amazon (AWS) is used by $111(55 \%)$ of the Sri Lanka companies in order to get different services and around 92 (45\%) are not using Google. Microsoft services are used by only $98(48 \%)$ organizations and around 105 (52\%) more than half of the companies are not using Microsoft services in Sri Lanka. Oracle services are used by 77 (38\%) organizations, while $126(62 \%)$ of the organization are not using Oracle. IBM services are used only by $62(31 \%)$ of the organizations and $141(69 \%)$ of the companies are not using IBM. Rack Space is also used by Sri Lankan companies but users are very poor. Around $8(4 \%)$ of the organizations are using this, while others around $195(96 \%)$ of the companies are not using this service. Therefore, comparing with other service providers, Rack Space is rendering poor services or organizations are not satisfied with their services. So this company has to take measures to action to adopt by Sri Lankan online organizations. 
Table 4: Cloud Service Provider in Sri Lanka

\begin{tabular}{ccccccccccccc}
\hline & \multicolumn{2}{c}{$\begin{array}{c}\text { Amazon } \\
\text { (AWS) }\end{array}$} & \multicolumn{2}{c}{$\begin{array}{c}\text { Microsoft } \\
\text { (Azure) }\end{array}$} & \multicolumn{2}{c}{ Google } & \multicolumn{2}{c}{ Rack Space } & & IBM & & Oracle \\
& Freq & $\%$ & Freq & $\%$ & Freq & $\%$ & Freq & $\%$ & Freq & $\%$ & Freq & $\%$ \\
No & 92 & 45 & 105 & 52 & 50 & 25 & 195 & 96 & 141 & 69 & 126 & 62 \\
Yes & 111 & 55 & 98 & 48 & 153 & 75 & 8 & 4 & 62 & 31 & 77 & 38 \\
Total & 203 & 100 & 203 & 100 & 203 & 100 & 203 & 100 & 203 & 100 & 203 & 100 \\
\hline
\end{tabular}

\section{SATISFACTION LEVELS OF OBSMES IN SRI LANKA}

According to the table 5, customer satisfaction levels are classified and measured using important key words such as level of satisfaction, level of reliability, level of data protection mechanism, satisfaction of the integrity and availability and level of disaster recovery arrangement of the data. As far as the satisfaction level of Cloud services are concerned that around $71(35 \%)$ organizations are responded as they are moderately satisfied, while $123(61 \%)$ organization are reported that they are very satisfied with the services provided by different types of Cloud services and 9 (4\%) of the organizations are reporting that they are extremely satisfied with the Cloud services. Most of the business organizations around $157(78 \%)$ are very satisfied with the reliability of services provided by service providers in Sri Lanka, while around 25 (12\%) of the organizations are moderately satisfied with their services of reliability and other around $21(10 \%)$ are extremely satisfied with the reliability of services. With satisfaction level of data protection mechanism, around $86(42 \%)$ of the organizations are moderately satisfied, while others around 117 (58\%) of the organizations are very satisfied. There is no organization who are extremely satisfied with this service. As far as the integrity and availability of the Cloud services are concern around $91(45 \%)$ of the organizations are moderately satisfied, while around $112(55 \%)$ organizations are very satisfied with this service and there is no organizations who are extremely satisfied. $62(31 \%)$ of the organizations are moderately satisfied with service provider's disaster recovery arrangement of data, while others around 141 (69\%) of the organizations are very satisfied with this service.

Table 5: Cloud Services satisfaction level by online business SMEs

\begin{tabular}{|c|c|c|c|c|c|c|c|c|c|c|}
\hline & \multirow{2}{*}{\multicolumn{2}{|c|}{$\begin{array}{l}\text { Satisfaction level } \\
\text { of service }\end{array}$}} & \multirow{2}{*}{\multicolumn{2}{|c|}{$\begin{array}{l}\text { Satisfaction } \\
\text { level of } \\
\text { reliability }\end{array}$}} & \multicolumn{2}{|c|}{ Satisfaction } & \multicolumn{2}{|c|}{ Satisfaction } & \multicolumn{2}{|c|}{ Satisfaction } \\
\hline & & & & & $\begin{array}{l}\text { level } \\
\text { prote } \\
\text { mech }\end{array}$ & $\begin{array}{l}f \text { data } \\
\text { on } \\
\text { ism }\end{array}$ & $\begin{array}{l}\text { level } \\
\text { integr } \\
\text { avail }\end{array}$ & $\begin{array}{r}\text { of } \\
\text { and } \\
\text { lity }\end{array}$ & $\begin{array}{l}\text { level } \\
\text { disas } \\
\text { recor }\end{array}$ & $\begin{array}{r}\text { of } \\
\text { and }\end{array}$ \\
\hline & Freq & $\%$ & Freq & $\%$ & Freq & $\%$ & Freq & $\%$ & Freq & $\%$ \\
\hline $\begin{array}{l}\text { Moderately } \\
\text { satisfied }\end{array}$ & 71 & 35 & 25 & 12 & 86 & 42 & 91 & 45 & 62 & 31 \\
\hline $\begin{array}{l}\text { Very } \\
\text { Satisfied }\end{array}$ & 123 & 61 & 157 & 78 & 117 & 58 & 112 & 55 & 141 & 69 \\
\hline $\begin{array}{l}\text { Extremely } \\
\text { Satisfied }\end{array}$ & 9 & 4 & 21 & 10 & - & - & - & - & - & - \\
\hline Total & 203 & 100 & 203 & 100 & 203 & 100 & 203 & 100 & 203 & 100 \\
\hline
\end{tabular}

\section{RECOMMENDATIONS AND CONCLUSIONS}

The first objectives of this study was set to identify Cloud Computing Practices among the OBSMEs who have successfully adopted Cloud computing in Sri Lanka. The findings revealed that there are four types (Frequently users, Sometimes users, occasionally users and usually users) of users of Cloud computing in OBSMEs in Sri Lanka have been identified. All the user are depending on Cloud computing for different purposes. $31 \%$ of users identified as frequently users for their ICT needs, while $69 \%$ of the user are identified as usually users of the technology who rely on Cloud computing for their ICT needs. Meanwhile, around $26 \%$ of the OBSMEs are identified as "Sometimes" for integration of Cloud Computing services and IT system locally, while around $55 \%$ of the online business SMEs are identified as "Frequently" and $20 \%$ of the online business SMEs are identified as regularly users of integration of
Cloud Computing services and IT system locally "Usually". Thereby, it is clear that none of the Cloud computing adopted OBSMEs are totally depending on Cloud computing technology in Sri Lanka. Therefore, the service providers must take necessary steps to overcome this problem.

The next aim of this study was to identify the cloud computing satisfaction levels of online business SMEs that have been successfully adopted in Sri Lanka. In this study, among the adopted SMEs, the findings revealed that, customer satisfaction levels are classified and measured using important key words such as overall level of satisfaction, level of reliability, level of data protection mechanism, satisfaction of the integrity and availability and level of disaster recovery arrangement of the data. As far as 
the overall satisfaction level of Cloud computing services are concerned around $35 \%$ of the organizations are responded that they are moderately satisfied, while $61 \%$ of the organizations are reported that they are very satisfied with the services provided by different types of Cloud computing services and around $4 \%$ of the organizations are responded that they are extremely satisfied with the Cloud computing services. Most of the SMEs are (78\%) very satisfied with the level of reliability of services in Sri Lanka, while around $12 \%$ of the SMEs responded that they are moderately satisfied with the services of reliability and others around $10 \%$ are extremely satisfied with the reliability of services. With satisfaction level of data protection mechanism is concerned, around $42 \%$ of the organizations are moderately satisfied, while others around $58 \%$ of the organizations are very satisfied. There is no organization who are extremely satisfied with this service. As far as the integrity and availability of the Cloud services are concern around $45 \%$ of the organizations are moderately satisfied, while around 55\% organizations are very satisfied with this service and there is no organizations who are extremely satisfied with. $31 \%$ of the organizations are moderately satisfied with service provider's disaster recovery arrangement of data, while others around $69 \%$ of the organizations are very satisfied with this service.

Therefore, in Sri Lankan context, Cloud computing business applications for customer service are vital for the success of any organization. Irrespective of whether you have a large or small business, such applications can bring key benefits like customer loyalty, customer satisfaction, and reduced costs your way. However, the overall satisfaction level of the SMEs is poor in Sri Lanka, therefore, it is necessary to concentrate in this area in order to increase satisfaction level which will make service provider to long sustain in their business in Sri Lanka.

The Third objective was to identify preferred Cloud services providers among online business organization in Sri Lanka. In this study, among the adopted SMEs, the findings revealed that, Google is in the top among service providers in Sri Lanka. According to table 4.12, around 153 (75\%) of the online business SMEs are using the service of Google, while $50(25 \%)$ of the organizations are not using Google. As far as Amazon is concerned it is used by $111(55 \%)$ of the Sri Lanka SMEs in order to get different services and around $92(45 \%)$ are not using Google. Microsoft services are used by only 98 $(48 \%)$ organizations and around $105(52 \%)$ more than half of the companies are not using Microsoft services in Sri Lanka. Oracle services are used by $77(38 \%)$ organizations, while $126(62 \%)$ of the organization are not using Oracle. IBM services are used only by $62(31 \%)$ of the organizations and $141(69 \%)$ of the companies are not using IBM. Rack Space is also used by Sri Lankan companies but users are very poor. Around $8(4 \%)$ of the organizations are using this, while others around 195 (96\%) of the companies are not using this service. Therefore, comparing with other service providers, Rack Space is rendering poor services or SMEs are not satisfied with their services. Therefore, service provides have to take measures to improve or enhance their services toward Sri Lankan online business SMEs by forming discussion groups specially in this area in order to enhance business agility.

\section{CONCLUSION}

Adopting this technology by SMEs in the Sri Lankan environment, has become of great importance, and this research can support maximise the potential benefits of the Sri Lankan SMEs' ICT implementation effort and support. In order to achieve successful enactment of Cloud computing, organisations must consider the potential factors that might affect the implementation process. This research attempted to enhance understanding of the factors influencing SMEs' decisions towards adopting Cloud computing, where Cloud adoption is still in its initial stage of implementation in various sectors in Sri Lanka. The findings of this research provides practical guidelines and contributions regarding Cloud computing Practicing levels, Satisfaction levels and Preferred Cloud Service providers of OBSMEs in Sri Lanka. Further, the output of this research has proved and the findings are supported with the research objectives in the study. In addition, the successful adoption of Cloud computing requires adequate government support in the form of revising the legislation related to data protection and reviewing policies and incentives in promoting the adoption.

Furthermore, the findings revealed that OBSMs in Sri Lanka has positive intentions and expectations to adopt towards Cloud computing. The majority of organizations emphasized that their organizations' needs can be met by Cloud computing. They agreed or strongly agreed with the statement that their organisation will take steps to adopt Cloud computing in the near future. These results can be considered important, given that the Cloud Service Providers (CSPs) continue to develop services specifically for SMEs in Sri Lanka. This study also contributes to a developing body of literature of the major factors of cloud computing adoption, which is vital for sustaining the business sectors and contributing towards the GDP of any country. Therefore, considering the above facts, this study makes an effort, firstly, to the non-adopter to create Cloud computing adoption plans and, secondly, for the service providers to improve their services and customer preferences in this context, finally the analysis of this study can assist them to understand clearly how and why choose to adopt cloud computing services and related factors in to their considerations. Furthermore, future research should be carried out in near future by considering the various companies and firms that deals with big data using quantities analysis.

\section{REFERENCES}

1. Ayoobkhan, A.L.M., \& David Asirvatham., 2017, “Adoption of Cloud Computing Services in Healthcare Sectors: Special Attention to Private Hospitals in Colombo District, Sri Lanka”, August 2017, Current Journal of Applied Science and Technology 23(232), 1-10, DOI:10.9734/CJAST/2017/34597.

2. Ayoobkhan, A.L.M., \& David Asirvatham., 2017, "Issues and Challenges Faced by Online Business Organizations in Adopting Cloud Computing: A Research Agenda". August 2017, International Journal of Computer Science and Software Engineering), DOI:10.23956/ijarcsse/V7I8/01805.

3. Alshamaila, Y, Papagiannidis, S \& Li, F 2013, 'Cloud computing adoption by SMEs in the north east of England: A multi-perspective framework', Journal of Enterprise Information Management, vol. 26 no. 3 , pp. $250-75$. 
4. Amini, M, Bakri, A, Nazli, SS, Javadinia, SA \& Tolooei, A 2014, "The role of top manager behaviours on adoption of Cloud computing for small and medium enterprises" Australian Journal of Basic and Applied Sciences (AJBAS), vol. 8, no. 1, pp. 490-8.

5. Abadi, DJ 2009, "Data management in the Cloud: Limitations and opportunities", IEEE Data Engineering Bulletin, vol. 32, no. 1, pp. 3-12.

6. Carcary, M, Doherty, E \& Conway, 2014, "The adoption of Cloud computing by Irish SMEs: An exploratory study", Electronic Journal Information Systems Evaluation, vol. 17, no. 1.

7. El-Gazzar, R. F., 2014, "A Literature Review on Cloud Computing Adoption Issues in Enterprises. In IFIP WG 8.6 International Conference on Transfer and Diffusion of IT", Aalborg, Denmark, June 2-4, 2014 (pp. 214-242). Springer Berlin Heidelberg.

8. Gupta, P, Seetharaman, A \& Raj, JR 2013, "The usage and adoption of cloud computing by small and medium businesses", International Journal of Information Management, vol. 33, no. 5, pp. 861-74.

9. Hwang, K \& Li, D 2010, "Trusted Cloud computing with secure resources and data coloring", Internet Computing, IEEE, vol. 14, no. 5 , pp. 14-22.

10. J. Li and J. Z. Liu, "Influence of Cloud Computing on Educational Informationization of China Rural Areas," The Proceedings of Information Science and Engineering Conference, Hangzhou, 2010, pp. 281-283.

11. Low, C, Chen, Y \& Wu, M 2011, "Understanding the determinants of cloud computing Adoption", Industrial Management \& Data Systems, vol. 111, no. 7, pp. 1006-23.

12. Muhammad H. Raza et al, 2015, "The Slow Adoption of Cloud Computing and IT Workforce, Procedia Computer Science",p- 114 1119, Available online at www.sciencedirect.com.

13. Mell, P \& Grance, T 2009, 'NIST Cloud computing programme', retrieved $23 \quad$ April 2012, <http://csrc.nist.gov/groups/SNS/cloud-computing/index.html>.

14. Mondal, A \& Misra, SC, 2011, "Identification of a company's suitability for the adoption of Cloud computing and modelling its corresponding Return on Investment", Mathematical and Computer Modelling, vol. 53, no. 3, pp. 504-21.

15. Oliveira, T, Thomas, M \& Espadanal, M 2014, "Assessing the determinants of cloud computing adoption: An analysis of the manufacturing and services sectors", Information \& Management, vol. 51, no. 5, pp. 497-510.

16. Prasad, A, Green, P, Heales, J \& Finau, G 2014a, "Towards a model of Cloud computing services for SMEs", in 25th Australasian Conference on Information Systems, Auckland, New Zealand.

17. Ramdani, B. 2008, "Technological, organisational and environmental factors influencing SMEsadoption of Enterprise Systems: a study in the Northwest of England". University of Manchester.

18. Rath, A, Mohapatra, S, Kumar, S \& Thakurta, R 2012, "Decision points for adopting cloud computing in small, medium enterprises (SMEs)", in 7th International Conference for Internet Technology and Secured Transactions, 10-12 December, London.

19. Senarathna, I, Warren, M, Yeoh, W \& Salzman, S 2016, "A conceptual model for Cloud computing adoption by SMEs in Australia”, in Delivery and adoption of Cloud computing services in contemporary organizations, IGI-Global, pp. 100-28.

20. [20] Saedi, Amin \& Iahad, Noorminshah A., 2013, Future Research on Cloud Computing Adoption by Small and Medium-Sized Enterprises: A Critical Analysis of Relevant Theories.

21. Son, I \& Lee, D 2011, 'Assessing a new IT service model, Cloud computing', in PACIS 2011 Proceedings, Queensland, Australia, vol. 179 , pp. $1-10$.

22. Saya S, Pee LG, Kankanhalli A. 2010, "The impact of institutional influences on perceived technological characteristics and real options in cloud computing adoption". Proceedings of the 31 st International Conference on Information Systems, St.Louis.

23. Tehrani, SR \& Shirazi, F 2014, "Factors influencing the adoption of Cloud computing by small and medium size enterprises (SMEs)', in Human interface and the management of information: Information and knowledge in applications and services", Springer, pp. 631- 42.

24. Wang, WYC, Rashi, A \& Chuang, H 2011, "Toward the trend of Cloud computing", Journal of Electronic Commerce Research, vol. 12, no. 4 pp. 238-42.

25. Zhang, Q, Cheng, L \& Boutaba, R 2010, "Cloud computing: State-of-the-art and research Challenges", Journal of Internet Services and Applications, vol. 1, no. 1, pp. 7-18.

26. Sekaran, U. and Bougie, R., 2013, "Research Methods for Business: A Skill-Building Approach". 6th Edition, Wiley, New York.

27. Colin Ting Si Xue1 and Felicia Tiong Wee Xin, 2016, Benefits and Challenges of the Adoption of Cloud Computing in Business, International Journal on Cloud Computing: Services and Architecture
(IJCCSA), 6(6)

28. Business Directory, Sri Lanka, 2017; Chamber of Commerce Sri Lanka, 2016/2017; http://www.lankayp.com; www.slt.lk; www.lankabusinessonline.com and www.ips.lk). 